https://helda.helsinki.fi

Learning by Making

Seitamaa-Hakkarainen, Pirita

Sage

2017

Seitamaa-Hakkarainen , P \& Hakkarainen , K 2017 , Learning by Making . in K Peppler (ed.)

, The SAGE encyclopedia of out-of-school learning . Sage , Thousand Oaks, California . https://doi.org/10.4135/978

http://hdl.handle.net/10138/310281

https://doi.org/10.4135/9781483385198.n164

unspecified

acceptedVersion

Downloaded from Helda, University of Helsinki institutional repository.

This is an electronic reprint of the original article.

This reprint may differ from the original in pagination and typographic detail.

Please cite the original version. 


\section{LEARNING BY MAKING}

Making things by hand is considered a fundamental characteristic of human creative activity. Crafts refers to the various kinds of skilled practices based on the predominant material used, such as textile, metal, and wood crafts. The status of crafts has varied over the decades, and crafts are often spoken of as opposed to arts, design and technology; crafts are said to represent mainly past and repetition of motor skills, not the creation of unique creative ideas. Craft is often treated as an oldfashioned tradition that does not belong to modern society or the 21 st century skills. Some researchers have argued that craft only applies in the material world; it involves only a physical object; such must be made by hand — substantially by one's hands alone and to some degree with the aid of power tools; and foremost, craft must involve traditional craft materials and techniques.

Over the past few years, however, there has been growing interest in crafts as people recognize the enjoyable experience of craft activities; some researchers have started to take a more favorable view of craft skills and craft ethos whereby these are regarded as inherent characteristics of all making activities. Various forms of handicraft, for example knitting, constitute very popular hobbies among young and elderly people. Making crafts has been considered as providing creative leisure and having therapeutic impact; it elicits experiences laden with pleasure. Recently, social and community facets are being included in craft activities: people are sharing their craft projects, exchanging their skills virtually by blogging, and participating in craft activities in various social networks. This entry discusses how craft and making have come to combine traditional and digital technologies, schools' approach to maker culture, the Finnish approach to integrating craft education and making activity into the school curriculum, and some of the practices found in schools where learning by making and invention is emphasized. 


\section{Combining Traditional and Digital Technologies}

Craft and making are more and more strongly related also to various digital tools being used, such as 3D printers, laser cutters, and e-textiles. Many craft projects involve parallel use of both traditional and digital technologies, such as using scissors in cutting textiles but also integrating a small, sewable circuit board and microprocessors in the design artifacts created. For example, designing an embroidered evening bag may include traditional hand embroidery technique for decoration of the surface and connecting conductive metallic threads together with the FLORA circuit board and color-changing NeoPixels LEDs that can be programmed to change colors in certain situations.

By integrating maker technologies with traditional craft methods and practices, participants are able to fabricate virtually any object without expensive resources. Such technologies also enable young children to construct complex controllable artifacts with hybrid material, digital, and virtual features. Moreover, these projects can be shared with interested peers by blogs or video blogs that allow followers to trace their progress in these creative projects. These new forms of constructing, sharing, and communicating crafts are referred to as a maker culture and a new maker movement has been established.

\section{Bringing Elements of Maker Culture to Schools}

Maker culture has been mostly developed in informal do-it-yourself activities and contexts where participants make personally, socially, and culturally valuable artifacts according to their interests and needs. Bringing elements of maker culture to schools to enrich science, technology, engineering, arts, and mathematics (STEAM) studies and engage students' motivation appears very promising. The educational value of participating in artifact making was already anticipated by progressive educational researchers, such as John Dewey and Seymour Papert. Stanford 
University's FabLearn Labs initiative aims at enriching educational practices with the new possibilities of various making technologies.

Learning by making entails, in accordance with Papert's constructionism, that learners are not only building conceptual knowledge but also creating new artifacts and cultivating new ways of thinking and acting. Designing and making is from the very beginning focused on creating and transforming design ideas into various material forms. Learning by making is a critical aspect of knowledge-creation-based learning, or learning that, beyond knowledge acquisition and social participation, involves systematic collaborative efforts in creating and advancing shared epistemic objects by means of externalizing design ideas and constructing various types of tangible artifacts.

Making is a very effective way of engaging students in a design mode that guides them to focus on the usefulness and adequacy of ideas and, moreover, invest efforts in the continuous improvement of ideas. In the context of design and craft, this has meant that design ideas are iteratively evaluated and refined, gradually transformed into various material artifacts; the makers create increasingly complex products. The important aspects of craft learning and craft making are "designerly" ways of thinking and the manipulation of materials and tools. Thus, the interaction between thinking and making is pivotal.

In many countries craft making is not, however, an integrated aspect of schooling, and research efforts have focused on after-school clubs and other informal contexts. The situation is, however, different in Scandinavian countries, especially Finland, as explained in the next section. Finland has a strong tradition of pursuing compulsory craft studies from first through seventh grade. It gives learning by making and inventing a central role in education, empowering students' personal and collaborative learning. Learning by making offers the promise to bring experts' authentic creative practices to schools so that students learn science and other subject domains through creative activities instead of merely as formal systems; this is likely to elicit the development of higher-order learning and thinking skills and associated collaborative competencies. 


\section{Finnish Tradition of Craft Education}

In many countries, the educational system rarely includes craft education in the core curriculum. Even design and technology education is a new arrival in education; in most Western countries it has been part of the school education only in the past three decades. Furthermore, there is huge variation between countries in how design and technology is included in the curriculum and used in the classroom. It can be a separate school subject that is either compulsory or optional, or a crosscurricular integrative activity.

However, in many Scandinavian countries, Finland included, craft education has been an independent and compulsory school subject. Craft education was already an important part of education when the Finnish school system was established in 1866, and it has since had a rather stable position in the National Core Curriculum for Basic Education. Finland's tradition of craft education provides ample opportunities to involve elementary and lower secondary school students in creative designing, in making, and in invention activities. There have been occasional discussions in Finland on whether craft education is still needed in the modern society; however, one of the prominent arguments for retaining craft education in school curriculum is that it provides new possibilities for creativity education in terms of bringing maker culture to school. It also provides an important platform for applying various digital technologies as well as learning to code in meaningful and authentic problem solving contexts. Moreover, it provides frames for conducting integrative thematic-study projects together with other school subjects.

A new national core curriculum was implemented in Finland in 2016. The national core curriculum is a set of regulations issued by the National Board of Education, and each municipality constructs its own local curriculum in compliance with these regulations. The national core curriculum strongly emphasizes both the integration of school subjects and multidisciplinary learning modules, also called integrative thematic-study projects or phenomenon-based studies. These learning modules engage teachers and students in designing study projects that integrate 
several school-subject domains around broad themes, such as humans and technology. The learning modules also highlight the use of investigative methods for socializing students to productive and creative use of knowledge. Co-teaching plays a crucial role in the process, so teachers representing several subject domains are involved (with students) in designing these projects. Schools and teachers have an important role in designing the local curriculum for steering and implementing the prescribed educational goals and tasks in accordance with local craft culture, connections to local museums or businesses, and similar considerations.

Craft education is a compulsory school subject in comprehensive education in Finland. The craft curriculum is made for pre-primary, primary school level (grades 1 to 3), intermediate level (grades 4 to 6) and junior high school level (grades 7 to 9). Craft education is an obligatory subject until the end of grade 7 and a voluntary school subject in grades 8 and 9. Further, some high schools can offer special craft programs or diploma work on a voluntary basis. The lesson hours for craft education vary from 2 to 3 hours a week depending on the grade level. In local curriculum there are also some possibilities for extra lessons that are directed to artistic and practical subjects such as craft, home economics, and visual arts. In the lower level of education (grades 1 to 4), the teacher can be the students' main classroom teacher who also specializes in craft education. In many schools, however, a craft teacher (having a master's degree in craft education) takes care of craft education lessons from grade 5 to grade 9.

All the schools have special classrooms for craft education: usually a classroom for textile techniques and another one for technical craft. These craft classrooms are well equipped, usually involving such instruments as sewing machines and sergers in textile craft classrooms and traditional and digital milling machine tools for wood and metal, and recently sometimes also 3Dprinters in technical ones. The craft teacher has responsibility for maintaining craft classes and supporting pupils' safety while they are using power tools. Consequently, the aim of the craft curriculum is also to guide the pupils in familiarizing themselves with many different materials, 
methods, and instruments as well as to encourage them to engage in persistent and responsible work in order to ensure work safety.

The Finnish curriculum emphasizes the importance of engaging pupils in the holistic craft processes from ideation to iterative testing and making, as well as reflective evaluation. The craft process is seen to consist of various phases: producing ideas, designing, experimenting, production, and application as well as documentation and assessment. Ideation and designing are integral parts of craft processes and craft can be seen as a way of materializing the design ideas.

Craft is a subject where multiple materials are used and the aim of curriculum emphasizes craft expression, design, and technology. Craft making is seen as exploratory, inventive, and experimental activity in its core nature. Various visual, material, and technical solutions as well as a range of production methods are expected to be used creatively. The instruction of craft education is not restricted to some special traditional craft techniques or materials, but puts emphasis on multimateriality and development of versatile working capabilities. In practice, however, some of common textile techniques (knitting, sewing), as well as technical work such as wood, metal, and electricity work are an important part of the content of curriculum. Further, the core curriculum of craft education emphasizes multimodality, documentation, and digitalization. Craft education develops pupils' spatial awareness, sense of touch, and manual skills, which promotes motor skills, creativity, and design skills. The significance of craft learning and making lies in persistent and innovative working processes and positive experiences that strengthen self-esteem and provide enjoyment.

The Finnish approach to bringing maker culture to schools relies on a close interaction between school subjects and collaboration with various experts, museums, and local communities. Social and digital technologies enable creation a new ecosystem of collaborative making in all places and spaces of school, with local and grass-roots-level initiatives. Investigators are exploring various ways of structuring the projects, affordances of different maker technologies, and 
integration of making processes with entrepreneurial education. Some schools are organizing annual invention events bringing professional inventors to share their experiences with students and comment on their inventions. A central belief guiding these efforts is that school learning would be a much more inspiring process if students could graduate from schools having a whole portfolio of inventions that they have created with their peers under the guidance of teachers and experts.

\section{Integrating Learning by Collaborative Making in Education}

Knowledge-creating learning is focused on organizing inspiring phenomenon-based and creative school projects in primary and lower secondary schools by relying on various traditional and digital making technologies and practices. Bringing elements of maker culture to schools and challenging students to pursue shared creative projects can elicit students' personal curiosity, shared excitement, and joint inspiration. Students will gain social recognition for such achievements. In schools where learning by making and invention is emphasized, the following practices can be found:

Students pursue knowledge-creating projects involving epistemic, technical, and aesthetic challenges.

The projects are often anchored in phenomenon-based themes that integrate several school subjects.

Projects may involve practicing such scientific practices as problem posing, experimenting, and seeking and building knowledge.

Students are guided to undertake various invention practices for improving their ideas: sketching, studying former inventions, prototyping, and jointly evaluating ideas-inprogress.

Instruments and methods of personal fabrication (e.g. coding, microprocessors, sensors, robotics, 3D printers, laser cutters, e-textiles, and various construction materials) are used to support knowledge creation. 
Co-invention engages students in designing and inventing their own artifacts and, thereby, building their own knowledge as well as their connections to the Internet of Things, in which devices are connected and communicate with each other through the Internet.

Students' creative activity has to be directed and structured, but stages and structures followed are open and flexible and vary according to contextual needs. Each project has a general theme, such as "finding a solution to an everyday problem or challenge," but the nature of the theme varies. Sometimes it is very broad and open, but in other cases it could be rather specific and constrained. Invention and knowledge creation are not possible without repeated creative efforts involving externalization and reflection, visualization, and prototyping of artifacts in making.

An important aspect of collaborative designing and making is working with shared design objects, such as visual representations, models, and concrete materials. Although students sometimes have sophisticated digital competences, they need teachers', parents' and experts' support in learning to use social and digital technologies creatively. Participation of parents, experts (e.g., inventors, museum pedagogies, scientists) and involvement of local communities depends on the contacts and preferences of schools and teachers.

\section{Pirita Seitamaa-Hakkarainen and Kai Hakkarainen}

See also Community-School Partnerships, Constructionist Learning, Constructivist Learning, Crafting, Creative Learning, Linking In-School and Out-of-School Learning, Makerspaces, STEAM-Based Approaches to Out-of-School Learning

\section{FURTHER READINGS}

Bereiter, C., \& Scardamalia, M. (2003). Learning to work creatively with knowledge. In E. De Corte, L. Verschaffel, N. Entwistle, \& J. van Merriënboer (Eds.), Powerful learning environments: Unraveling basic components and dimensions (pp. 55--68). (Advances in Learning 
and Instruction Series). Oxford, UK: Elsevier Science.

Blikstein, P. (2013). Digital fabrication and "making" in education: The democratization of innovation. In J. Walter-Herrmann \& C. Buching (Eds.). FabLabs: Of machines, makers, and inventors. Bielefeld: Transcript.

Kangas, K., Seitamaa-Hakkarainen, P., \& Hakkarainen, K. (2013). Design Expert's Participation in Elementary Students' Collaborative Design Process. International Journal of Technology and Design Education. Volume 23, Issue 2, 425-442

National Core Curriculum for Basic Education 2014. (2016). Finnish National Board of Education.

Paavola S. \& Hakkarainen, K. (2014). Trialogical approach for knowledge creation. In Tan S-C., Jo, H.-J., \& Yoe, J. (Eds.), Knowledge creation in education. Education Innovation Series by Springer.

Seitamaa-Hakkarainen, P., Viilo M. \& Hakkarainen K. (2010). Learning by Collaborative Designing: Technology-enhanced Knowledge Practices. International Journal of Technology and Design Education. Vol. 20 Issue 2, 109-136. 